\title{
Identification and cloning of a glycoprotein hormone receptor from sea lamprey, Petromyzon marinus
}

\author{
Mihael Freamat, Hiroshi Kawauchi ${ }^{1}$, Masumi Nozaki ${ }^{2}$ and Stacia A Sower \\ Department of Biochemistry and Molecular Biology, University of New Hampshire, Room 310, 46 College Road, Durham, New Hampshire 03824, USA \\ ${ }^{1}$ Laboratory of Molecular Endocrinology, School of Fisheries Sciences, Kitasato University, Sanriku, Iwate 022-0101, Japan \\ ${ }^{2}$ Sado Marine Station, Niigata University, Sado, Niigata 952-2135, Japan \\ (Requests for offprints should be addressed to S A Sower; Email: sasower@ cisunix.unh.edu)
}

\begin{abstract}
A full-length transcript encoding a functional lamprey glycoprotein hormone receptor I (IGpH-R I, GenBank AY750688) was cloned from the testes of the sea lamprey, Petromyzon marinus, using the GpH-R protein fingerprint GLYCHORMONER from the PRINTS database. The present study is the first to identify a GpH-R transcript in an agnathan, which is one of the only two representatives of the oldest lineage of vertebrates. The 719-amino acid full-length cDNA encoding IGpH-R I is highly similar and is likely a homolog of the vertebrate GpH-Rs (including LH, FSH, and TSH receptors). The key motifs, sequence comparisons, and characteristics of the identified $\mathrm{GpH}-\mathrm{R}$ reveal a mosaic of features common to all other classes of $\mathrm{GpH}-\mathrm{Rs}$ in vertebrates. The IGpH-R I was shown to activate the cAMP signaling system using human chorionic gonadotropin in transiently transfected COS-7 cells. The highest expression of the receptor transcript was demonstrated in the testes using reverse transcriptase-PCR. Lower levels of the receptor transcript were also detected in brain, heart, intestine, kidney, liver, muscle, and thyroid. The high expression of IGpH-R I in the testis and the high similarity with gnathostome gonadotropin hormone receptors suggest that IGpH-R I functions as a receptor for lamprey gonadotropin hormones. We hypothesize from these data that there is lower specificity of gonadotropin and its receptor in agnathans and that during co-evolution of the ligand and its receptor in gnathostomes, there were increased specificities of interactions between each $\mathrm{GpH}(\mathrm{TSH}, \mathrm{LH}$, and FSH) and its receptor.
\end{abstract}

Journal of Molecular Endocrinology (2006) 37, 135-146

\section{Introduction}

Gonadotropin and thyrotropin hormone actions are mediated through a subfamily of G-protein coupled receptors (GPCR), namely the glycoprotein hormone receptors (GpH-Rs) (Combarnous 1992). Known $\mathrm{GpH}-\mathrm{Rs}$ share a number of unique features. They are composed of two functionally distinct modules of similar size, an extracellular $\mathrm{N}$-terminal domain followed by a prototypical GPCR segment. The extracellular N-terminal domain is primarily responsible for high-affinity hormone binding and contains a central portion of nine Leu-rich repeat (LRR) motifs, flanked by $\mathrm{N}$ - and C-terminal Cys-rich clusters. The C-terminal half of the receptor contains a transmembrane region with the typical seven hydrophobic transmembrane $\alpha$-helices, connected by intra- and extracellular loops and an intracellular C-terminal domain (Grossmann et al. 1997, Dufau 1998, Ascoli et al. 2002, Moyle et al. 2005). To date, approximately 79 GpHRs have been identified and described in 36 different species, mostly in mammals and also in three species of birds, two species of reptiles, one amphibian, and ten species of fish (Hovergen Database, http:// pbil.univ-lyon1.fr). There have been no GpH-Rs described in any species of agnathans.

The glycoprotein hormone family consists of two gonadotropin hormones (GTHs), luteinizing hormone (LH) and follicle-stimulating hormone (FSH), and one thyroid-stimulating hormone (TSH). They are part of the cystine-knot family of growth factors with two noncovalently bound subunits, $\alpha$ and $\beta$. The $\alpha$ subunit is common within a single species (Kawauchi et al. 1989). The $\beta$ subunits are homologous and convey hormone specificity (Themmen \& Huhtaniemi 2000, Szkudlinski et al. 2002, Swanson et al. 2003). Therefore, these glycoprotein hormones are believed to have evolved from a common ancestral molecule through duplication of $\beta$-subunit genes and subsequent divergence (Moyle $e t$ al. 1994, Li \& Ford 1998). Two GTHs have been identified in all taxonomic groups of gnathostomes, including actinopterygians (Suzuki et al. 1988, Kawauchi et al. 1989, Querat et al. 2000), sarcopterygians (Querat et al. 2004), and chondrichthyans (Querat et al. 2000), and only recently in jawless vertebrates (agnathans) (Sower et al. 2006). 
Lampreys (Petromyzontidae), along with hagfish (Myxinae), are the only living representatives of the agnathans, the most ancient class of vertebrates, whose lineage dates back over 530 million years (Kuratani et al. 2002). Although the problem of the evolutionary relationship between these two surviving groups of agnathans has not yet come to a definitive conclusion, it is well accepted that they form a monophyletic group to the rest of vertebrates the gnathostomes. Lamprey and gnathostomes share the same jawless ancestors and this is of foremost importance for the contribution of the study of lamprey in understanding the evolutionary mechanisms which led to the definition of the functional architecture of endocrine control in vertebrates. This is particularly true for the pituitary $\mathrm{GpH} / \mathrm{GpH}-\mathrm{R}$ pairs, since it is estimated that the structural and functional divergence of $\mathrm{GpH}-\mathrm{Rs}$ coincide with the geological time of divergence of the gnathostomes from their jawless ancestors.

Lampreys, which express two forms of gonadotropin releasing hormone (GnRH), lamprey GnRH-I and -III (Gorbman \& Sower 2003), are important to our understanding of the reproductive success of the first vertebrates and are likely to have retained key characteristics of the ancestral GTH and GTH-R(s) from which modern GTH and GTH-Rs arose. Although the lamprey GnRH-I and -III with a known role in the hypothalamic-pituitary-gonadal axis of this animal have been well demonstrated (Sower 2003), the lamprey homologs of gnathostome GTHs, TSHs, and their receptors have eluded numerous attempts in identification. Here, we report the identification of a functional lamprey GpH-R I (GpH-R I) similar to gnathostome GTH-Rs, exhibiting its highest level of expression in the testis of the lamprey.

\section{Materials and methods}

\section{Animals}

Fifty reproductive mature sea lampreys were collected from Cocheco River fish ladder in Dover, NH, USA during their upstream migration in May. They were transported to the Anadromous Fish and Aquatic Invertebrate Research (AFAIR) Laboratory of the University of New Hampshire and maintained under continuous flow of river water and aeration at ambient temperature until sampled. Sea lamprey tissue samples were collected at the UNH AFAIR laboratory. Approximately $100 \mathrm{mg}$ tissue fragments were flash frozen in liquid nitrogen and then kept on dry ice until stored at $-80^{\circ} \mathrm{C}$.

\section{Degenerate primers design}

Degenerate primers were designed using the PRINTS database (http://umber.sbs.man.ac.uk/dbbrowser/ PRINTS/) GLYCHORMONER protein fingerprint alignment blocks as input. The PRINTS database contains protein fingerprints derived by extensive statistical analysis of protein alignments for identification of the alignment blocks (fingerprint elements), which uniquely identify the corresponding protein family (Attwood et al. 1998, 2003). Selection of primers was based on a simple optimality score calculated using the following formula: $S=\operatorname{sum}\left(s_{\mathrm{i}}\right) / D$, where $S$ is the final optimality score for a given degenerate primer candidate, $s_{\mathrm{i}}$ are the scores assigned to each of the properties of the individual oligos corresponding to the degenerate primer candidate and $D$ is the degeneracy of the primer.

\section{RNA isolation and degenerate PCR amplification}

Total RNA of tissues was extracted using the TRI-reagent (MRC, Cincinnati, OH, USA) method following the manufacturer's protocol. Single-strand cDNA was synthesized from $c a 1 \mu \mathrm{g}$ testis total RNA using the avian myeloblastosis virus reverse transcriptase and the Not-I poly-A anchored reverse primer from Amersham. Amplification with degenerate primers (IDT, Coralville, IA, USA) was performed with $1.25 \mathrm{U}$ Taq Polymerase (Promega Corp.) in $25 \mu \mathrm{l}$ reaction volume containing $200 \mathrm{nM}$ dNTP, $3 \mathrm{mM} \mathrm{MgCl} 2,0 \cdot 5 \mu \mathrm{l} \mathrm{GC-Melt} \mathrm{(Clontech)}$ and $0 \cdot 4 \mu \mathrm{M}$ of each primer under the following cycling conditions: (1) $30 \mathrm{~min}$ initial incubation at $65^{\circ} \mathrm{C}$, (2) initial denaturation $5 \mathrm{~min} / 95^{\circ} \mathrm{C}$, and (3) 40 cycles with $1 \mathrm{~min} / 94^{\circ} \mathrm{C}$ denaturation, $30 \mathrm{~s} / 65^{\circ} \mathrm{C}$ annealing, $30 \mathrm{~s} / 72^{\circ} \mathrm{C}$ extension. The PCR products were separated on NuSieve low-melting temperature agarose gel (FMC BioProducts, Rockland, ME, USA) and excision of DNA bands was followed by in-gel ligation into the pGEM-T Easy vector (Clontech). The ligation product was then used for transformation of JM109 highly competent cells (Clontech), which were plated on Luria-Bertani (LB) plates treated with IPTG/X-Gal for blue/white colony screening. Positive colonies were grown overnight in LB medium with ampicillin. Plasmid DNA was isolated using the Wizard(r) DNA Purification System (Promega) and sequenced at the Sequencing Service of the University of Utah. At least two samples resulted from different amplification experiments were sequenced for each amplicon.

\section{RT-PCR assay}

Gene-specific primers derived from the transmembrane region of the putative $1 \mathrm{GpH}-\mathrm{R}$ identified by degenerate PCR were used for a semiquantitative estimation of the expression of the corresponding genes in various lamprey tissues (brain, heart, intestine, kidney, liver, muscle, testes, and thyroid) by RT-PCR. Total RNA was extracted using the TRI-reagent (MRC) method as previously described. 
The amount and quality of RNA were estimated by optical density measurements at 260 and $280 \mathrm{~nm}$ in $10 \mathrm{mM}$ Tris buffer $(\mathrm{pH} \mathrm{8.0)}$ and by non-denaturing agarose gel electrophoresis. Ten micrograms total RNA samples were incubated with 1 IU RQ1 DNase (Promega) in PCR buffer for $2 \mathrm{~h}$ at $37^{\circ} \mathrm{C}$ to remove any contaminating genomic DNA. Aliquots of the DNase-treated total RNA were run on a non-denaturing agarose gel and the concentration of RNA for PCR was normalized based on the relative intensity of the $28 \mathrm{~S}$ rRNA bands. An alternate method for normalization of the total RNA amount has been employed by spotting equal volumes $(1 \mu \mathrm{l})$ of the DNase-treated total RNA on an agarose gel. The integrated optical density of each spot was calculated after background subtraction (NIH/ImageJ application) and the obtained values were then used for correction of the concentrations of the total RNA samples used as templates in reverse transcriptase (RT)-PCR. The onetube AccessQuick RT-PCR system (Promega) was used for amplification of a $377 \mathrm{bp}$ fragment from the TM region of lGpH-R I (primers C2P6f/C2P2r). A no-(RT) control reaction was run for every sample. The PCR program was: initial denaturation $5 \mathrm{~min} / 95^{\circ} \mathrm{C}$, denaturation $40 \mathrm{~s} / 94{ }^{\circ} \mathrm{C}$, annealing $30 \mathrm{~s} / 63^{\circ} \mathrm{C}$, extension $45 \mathrm{~s} / 72^{\circ} \mathrm{C}$ for 40 cycles, and final extension step $5 \mathrm{~min}$ at $72^{\circ} \mathrm{C}$.

\section{Cloning of full-length IGpH-R I cDNA}

Ten micrograms lamprey testes total RNA was reverse transcribed at $55^{\circ} \mathrm{C}$ for $1 \mathrm{~h}$ with SuperScript III RT (Invitrogen) in the presence of the CDS III primer and SMART IV template-switch oligo (Clontech) followed by 15-min incubation at the same temperature in the presence of $5 \mathrm{mM} \mathrm{MnCl}_{2}$ to enhance the templateswitch extension of cDNA. The reaction product was then treated with RNase $\mathrm{H}$ to release the single-strand cDNA from the cDNA-RNA heteroduplexes. The $5^{\prime}$ end of the lGpH-R I transcript was cloned by step-out RACE (SO-RACE), while the $3^{\prime}$ end was amplified using a gene-specific forward primer and the CDS III primer (Clontech). The SO-RACE used a modified version of the two amplification stages protocol described in Matz et al. (2003). The PCR products whose agarose gel migration pattern matched the one predicted from the positioning of the gene-specific primers were isolated, cloned, and sequenced as described previously. The $5^{\prime}$ and $3^{\prime}$ fragments were assembled using the pregap4 and gap4 programs from the Staden Package (http://staden.sourceforge.net/; Staden 1996).

\section{COS-7 expression construct}

Gene-specific primers (IGpH-R I_TOPOf and lGpH-R I_TOPOr respectively) containing the START and STOP codons were designed and used for cloning of the full-coding sequence of lGpH-R I. Briefly, lamprey testes total RNA were reverse transcribed with SuperScript III as previously described and the cDNA used for PCR amplification of lGpH-R I full-coding sequence with Phusion High-Fidelity DNA Polymerase (Finnzymes/NEB, Ipswich, MA, USA). The PCR product was ligated into the pcDNA 3.1/V5-His-TOPO vector (Invitrogen), cloned in TOP10 competent cells and checked by sequencing using vector-specific sequencing primers as well as gene-specific primers to ensure full coverage of the lGpH-R I coding domain sequence (cds). The EndoFree Plasmid Maxi Kit (Qiagen) was used for preparation of the DNA for mammalian cell transfections.

\section{Transient expression of IGpH-R I in COS-7 cells and CAMP accumulation assay}

The COS-7 cell line was purchased from American Type Culture Collection (Manassas, VA, USA). Cultures were transiently transfected with lGpH-R I construct and with blank pcDNA3.1 vector (negative control) using lipofectamine or lipofectamine 2000 methods (Invitrogen) in 24-well plates according to the manufacturer's instructions. Efficiency of transfection was estimated by control transfections with pcDNA3 1/V5His-LacZ vector followed by B-Gal staining (Invitrogen). The putative lamprey native ligand for this receptor was not available at the time of these experiments, so human chorionic gonadotropin (hCG, Sigma-Aldrich) was used instead for stimulation of transfected COS-7 cells. Intracellular accumulation of cAMP was estimated after 3-h incubation with various concentrations of hCG in Krebs-Ringer buffer containing $0 \cdot 1 \%$ pyrogen free BSA (Calbiochem) and $0 \cdot 1 \mathrm{mM}$ IBMX (Sigma). The buffer was aspirated, cells lysed in $0 \cdot 1 \mathrm{M} \mathrm{HCl}$ or in an Amersham proprietary lysis reagent and concentration of cAMP measured by radioimmunoassay (RIA). The ${ }^{125}$ I cAMP tracer and cAMP antiserum were a generous gift from Dr William Moyle (University of Medicine and Dentistry of New Jersey, Piscataway, NJ, USA). Results are expressed as fold increase over the basal level of the intracellular cAMP \pm s.E.M. versus the concentration of hCG in the stimulation medium.

\section{Effect of IGpH-R on basal levels of intracellular cAMP}

To estimate the effect of lGpH-R I on the basal production of cAMP in transiently transfected COS-7 cells a secreted alkaline phosphatase (SEAP)-based reporter system was used. It showed a higher sensitivity compared with the RIA procedure in experiments, where the rat LH-R was stimulated with hCG or ovine LH (data not shown). The reporter plasmid cAMP responsive elements (pCRE)-SEAP contains three CRE upstream from the gene encoding a modified human 
placental alkaline phosphatase, which is secreted into the culture medium upon stimulation by intracellular cAMP. COS-7 cells were co-transfected with various amounts of pcDNA3 $\cdot 1 / 1 \mathrm{GpH}-\mathrm{R}$ I or empty pcDNA3 1 $(0 \cdot 05,0 \cdot 1,0 \cdot 2,0 \cdot 4,0 \cdot 6$, and $0 \cdot 8 \mu \mathrm{g})$ and $0 \cdot 8 \mu \mathrm{g}$ pCRESEAP or pTAL-SEAP (negative control) in 24-well plates with $2 \mu$ lipofectamine 2000 transfection reagent (Invitrogen) following the manufacturer's protocol. After 24-h incubation, the culture medium was aspirated and replaced with low serum Opti-MEM medium and incubated overnight. The next day the medium was replaced with serum and phenol red free Dulbecco's modified Eagle's medium (DMEM; HyClone, Logan, UT, USA) containing $0 \cdot 1 \%$ BSA (Calbiochem) with or without $0 \cdot 1 \mathrm{mM}$ IBMX. A third treatment consisted of $0 \cdot 1 \% \mathrm{BSA}, 0 \cdot 1 \mathrm{mM}$ IBMX, and $5 \mu \mathrm{M}$ forskolin DMEM for each lGpH-R I vector amount for normalization of the transfection efficiencies. After 18-h incubation, the medium was collected, centrifuged for $10 \mathrm{~min}$ at $10000 \mathrm{~g}$ at $4{ }^{\circ} \mathrm{C}$ then heated at $65^{\circ} \mathrm{C}$ for $30 \mathrm{~min}$ to eliminate the intrinsic alkaline phosphatase activity. A $20 \mu \mathrm{l}$ aliquot of each sample was then mixed with reaction buffer $(50 \mathrm{mM}$ Tris, $\mathrm{pH} 8 \cdot 2)$ containing $28 \mathrm{mM}$ pNPP (para-nitrophenyl phosphate) alkaline phosphatase chromogenic substrate and then incubated at $37^{\circ} \mathrm{C}$. The optical density was read at $405 \mathrm{~nm}$ on a microplate autoreader (BioTek, Instruments, Winooski, VT, USA) at approximately 3-h time intervals.
The results reported here are derived from end-point optical density measurement data obtained after approximately 24-h incubation. Absorbance in each well was corrected by subtraction of the pTAL-SEAP corresponding measurement and normalized with respect to the corresponding response to forskolin treatment. The same procedural outline was applied for analysis of the effect of different glycoprotein hormone treatments (hCG, ovine $\mathrm{LH}$, and ovine TSH) on activation of cAMP-mediated signal transduction by lGpH-R I.

\section{Software applications}

Assembling of sequencing readings was performed with the pregap4 and gap4 programs from the Staden Package (Staden 1996). Sequence alignments were performed using the ClustalW (Thompson et al. 1994) method. The signal peptide cleavage site was predicted using the SignalP (Nielsen et al. 1997) program (http://www.cbs.dtu.dk/services/SignalP/). Transmembrane regions were characterized from the thermodynamic profile of the region with programs from the European Molecular Biology Open Source Software (http://emboss.sourceforge.net/) (EMBOSS) package (octanol), the GPCR-specific Prosite (Bucher \& Bairoch 1994) signature was also identified using the Prosite motif finder from EMBOSS package (patmatmotifs) with a locally installed copy of the Prosite database.

Table 1 Oligonucleotides used for detection, RACE, RT-PCR, and functional expression of IGpH-R I

Sequence

\section{Name}

Forward primers

GHRS1_128f

GHRS2_256f

GHRS7_512f

C2P6f

5 proxB

Udist

IGpHRI_TOPOf

TTYAAYCCSTGCGARGAYATCATGGGMTAYGA

TAYAARCTSACSGTSCCSCGCTTYCTSATGTG

ATCACSGTSACSAAYWSCAARATCCTSCTSGT

CATCAGCAGCTACTCCAAGGTGAGCATTTG

CGACGTGGACTATCCATGAACGCAAAGCAGTGGT

ATCAACGCAGAGT

TCGAGCGGCCGCCCGGGCAGGTCGACGTGGACT

ATCCATGAACGCA

Reverse primers

GHRS7_512r

GHRS8 $512 r$

GHRS3_144r

C2P2r

CDS III

CACCATGGGTTGGGAGCACCGTAGGACGTC

AGSAGGATYTTGSWRTTSGTSACSGTGATSAG

RAAYTTGSWSAGSAGGATRAARAARTCGCGGC

CAKCCVGCKCCSGTCTGCCARTCGATVGCGTG

AAGCTCTTGGTGAAGATGGCGTAGAGTAAGGG

ATTCTAGAGGCCGAGGCGGCCGACATGTTTTTTTT

TTTTTTTTTTTTTTTTTTTTTTNN

IGpHRI_TOPOr CGTACGGCGGTGTAATTGAGCCGCGTTACG

GSP6r1

SP1C2r1

GSP7r1

SP1C2r2

$\mathrm{C} 2 \mathrm{P} 2 \mathrm{r}$

\section{Comments}

GLYCHORMONER element 1 GLYCHORMONER element 2

GLYCHORMONER element 7

Gene-specific primer for IGpH-R I RT-PCR assay

Step-out RACE $5^{\prime}$ adaptor 1 (Matz et al. 2003)

Step-out RACE $5^{\prime}$ adaptor 2 (Matz et al. 2003)

$5^{\prime}$ Primer for cloning the IGpH-R I cds for functional studies

GLYCHORMONER element 7 GLYCHORMONER element 8

GLYCHORMONER element 3

Gene-specific primer for IGpH-R I RT-PCR assay

SMART cDNA library construction kit (Clontech)

$3^{\prime}$ Primer for cloning the IGpH-R I cds for functional studies

Gene-specific primer for second stage $5^{\prime}$ SO-RACE

Gene-specific primer for second stage 5' SO-RACE

Gene-specific primer for second stage 5' SO-RACE

Gene-specific primer for second stage 5' SO-RACE

Gene-specific primer for first stage $5^{\prime}$ SO-RACE

$\mathrm{N}=$ any nucleotide, $\mathrm{Y}=\mathrm{C}$ or $\mathrm{T}, \mathrm{R}=\mathrm{G}$ or $\mathrm{A}, \mathrm{M}=\mathrm{A}$ or $\mathrm{C}, \mathrm{W}=\mathrm{A}$ or $\mathrm{T}, \mathrm{S}=\mathrm{G}$ or $\mathrm{C}, \mathrm{K}=\mathrm{G}$ or $\mathrm{T}$. 
For identification of protein motifs and patterns, the Prosite (http://ca.expasy.org/prosite) and InterPro (http://www.ebi.ac.uk/interpro/) search services were used with the lGpH-R I amino acid sequence as query. The maximum parsimony algorithm as implemented in the protpars application of the PHYLogeny Inference Package (PHYLIP; Felsenstein 1989) version 3.6 was applied to 1000 bootstrap replica (seqboot, PHYLIP package) of the initial amino acid sequence, then the consensus tree was derived using the consense program from the same package. Analysis of the RT-PCR gel images was performed with Image J application from NIH (Abramoff et al. 2004). Functional data analysis and graphing were performed in Prism (GraphPad, San Diego, CA, USA).

\section{Results}

Five distinct primer pairs: GHRS1_128f/GHRS7_512r, GHRS2_256f/GHRS8_512r, GHRS2_256f/GHRS7_512r, GHRS2_256f/GHRS3_144r, and GHRS7_512f/

5 atgggttgggagcaccgtaggacgtcgtggggggccetggtcgcgctctggctccaggttctggcgctaccgccgaaggtccaggggggcgcgtgctccc 104

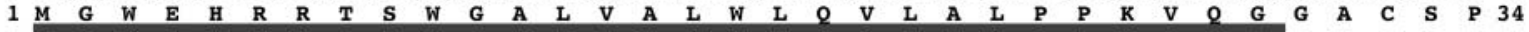

105 ccgggtgcgtgtgcgcgcacgactggatgaacttggtgcagtgcgtgggcgggaagacgctggagctgagcctgctgccggcacacacgcagcacctggt 204

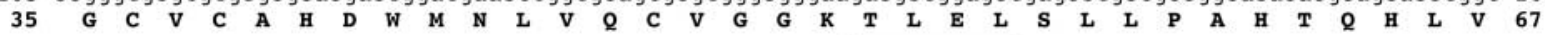

205 gttgatgaacacagttatcgaacgtgtcccgtcaggagccttctccaggctgagaacgtcacgaaaltcgacatcttagtttccaggcacctgcgcagc 304

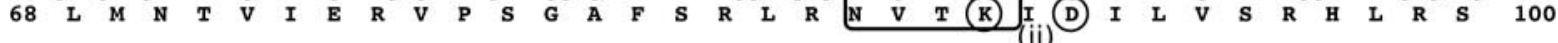
305 ttggaggccatgtccttctcccgtctctcgcagctgcaggacatagaaatccgcaacgccaatcgccttgcctacatccacagggacgcgttccacgagc 404

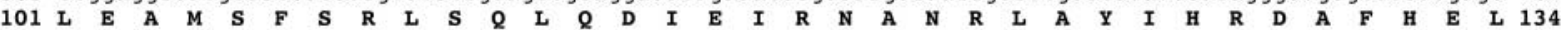
405 tgcccagcctcaggttcctgggaatcgccaacacggccattgagtgtttcccgcacgtgggcaagatccagtccacagttctcagcttcatcctcgaaat 504

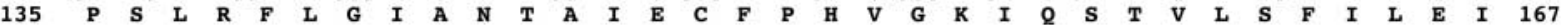
505 cctggacaaccccatgattgacctcatccccgcaaacgctctgcaaggtctcagctccgggtcgctcatcgtgaggctcttcaacaacaagtttgcgaaa 604

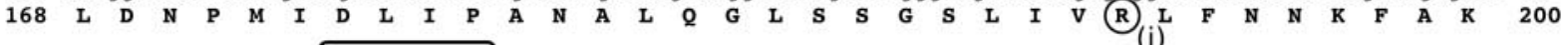
605 atcgaagacttcgccttdaacgcgaccatdetggacctgctggacctccacaacaatgacagactgtgggccatcggcgaggatgccttcagtggaatcc 704

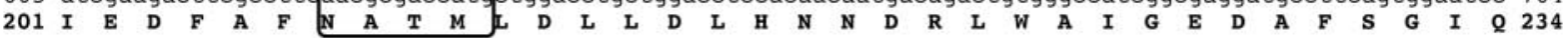
705 aggagaactctttcatactggacgtgtcccgtacctccgtgcgctcgcttccgcgccacgggctgcagcacgtgtggaagctgatggcgaacgccgcgtg 804 $\begin{array}{llllllllllllllllllllllllllllllllllllll}235 & \text { E } & \text { N } & \text { S } & \text { F } & \text { I } & \text { L } & \text { D } & \text { V } & \text { S } & \text { R } & \text { T } & \text { S } & \text { V } & \text { R } & \text { S } & \text { L } & \text { P } & \text { R } & \text { H } & \text { G } & \text { L } & \text { Q } & \text { H } & \text { V } & \text { W } & \text { K } & \text { L } & \text { M } & \text { A } & \text { N } & \text { A } & \text { A } & \text { W } & \text { 267 }\end{array}$ 805 gcatctcaagcagctgcccccatgggcagcttctcctcgctgtgctccgcoaacctcacctackcaagccactgctgcgttttctggcaccgcaaggcg 904

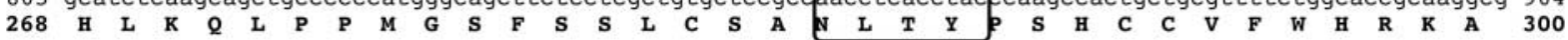
905 gcacaggggtgccacgcagacatctacatggaccaggagctccagaacgagagcttcgcctcgagcgacttcgacttggtgcagtgcgctccggagcccg 1004

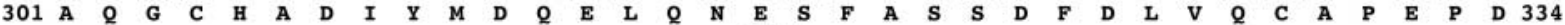
1005 acgecttcaacccetgcgaggacctcatgggccaccagctgctgcgcctcagcgtgtggtttgtgagcgtcctcgccgtcctgggcaactccatcgtcat 1104

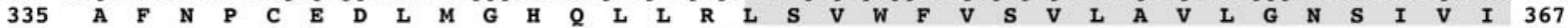
1105 cctcgtcatcctgagcagcegctacaagctggccgtgccacgcttcctcatgtgcaacctggcettcgccgacctctgcatgggcgtgtatctactcaca 1204

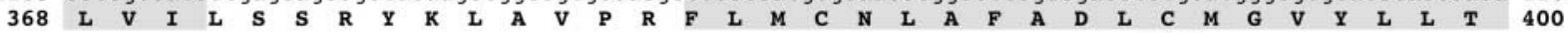

1205 atcgegtccttcgacgtgtacacccgcggcgagtatcacaaccacgccatcgactggcagacgggcetcggctgccgactcgcgggcttcctcacggttt 1304

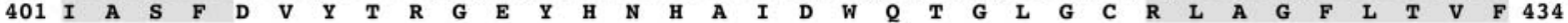

1305 tctcctccgagctgtcggtcttcacgctcaccgtgatcacggtggagcgctggcacaccatcatctacaccatgcgcctcgaccgcaaggtgtcctcggc 1404

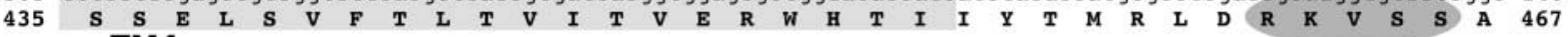
TM4

1405 gcaggcggtcaccatcatggcgtcgccetgggctctggcgctggtcctggctgcectgcccetcgctggcatcagcagctactccaaggtgagcatttgc 1504

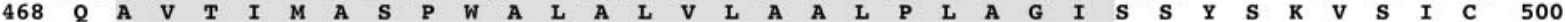

1505 ctgccatggacatcgagacgctgccatcgcaggcctacgtccaactcatcctgggcctcaacatcctggcgttcctcgtcatctgcgtgtgctacgcge 1604

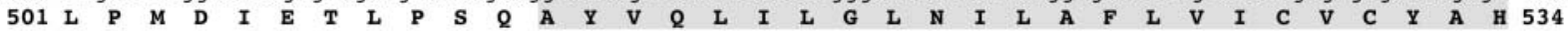
1605 acatctactcaacggttaggaacccgagctataacttgggcagccacgatgccaagatcgccaagcgcatggccgtcctcatcttcaccgacttcacctg 1704

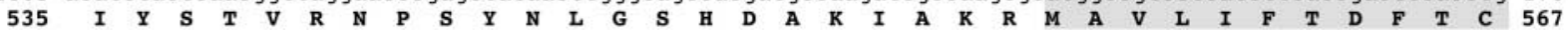

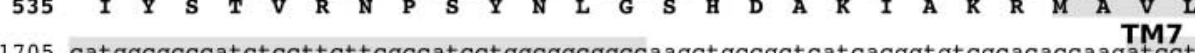

1705 catggcgcccatctccttcttcgccatcctggcggcggccaagctgccgctcatcacggtgtcgcacaccaagatcctgctcgtgctcttctacccgctc 1804

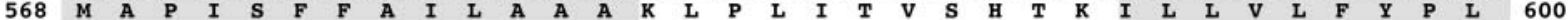

1805 aatgcgtgcgccaaccccttactctacgccatcttcaccaagagcttccgccgagacgtctttatcctgctgagccgcgtggggttgtgcgagcgccgcg 1904

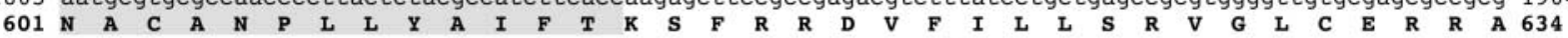

1905 cgcagcgccaccgtggccaggtggtgtcaggcggccaccceggcctgcadaatggcagcgtoleggtcatcatcaggggcggcggtggtggaagccagga 2004

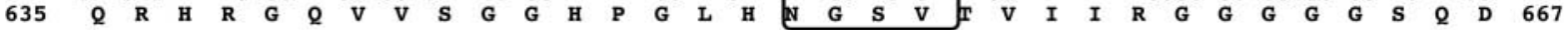

2005 tctgaatggcggtggtggtgccagcggtggcggcggcggtggtggtggcggtgatggtggttgtggtggcagtggtggtgggcttggcgtgaagatggca 2104

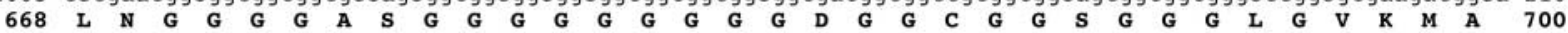

2105 ggcgttggtgccgtggccagcggttggctccgggcccacgcgggctgtcatggtcgtaa 2164

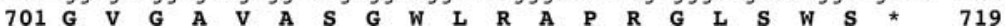

Figure 1 The nucleotide sequence and virtual translation of IGpH-R I coding domain sequence. The signal peptide is underlined. Transmembrane regions are shaded and labeled accordingly to their $\mathrm{N}$-terminal border; putative glycosylation motifs are marked by rounded corner boxes; the protein kinase putative phosphorylation sites are marked by shaded ellipses. Specific residues and motifs mentioned in text are encircled and labeled. *indicate STOP codon in nucleotide sequence. 
GHRS8_512r (see Table 1) amplified DNA fragments with sizes varying between 150 and $800 \mathrm{bp}$ highly similar with gnathostome GpH-Rs. The sequencing readings were assembled in gap4 (Staden package) and the resulting contig approximately $800 \mathrm{bp}$ has been named lGpH-R I. A smaller number of readings were assembled into a second, distinct contig, which we consider a fragment of a second glycoprotein hormone receptor II (IGpH-R II).

Combination of $3^{\prime}$ and $5^{\prime}$ RACE reactions resulted in a set of overlapping DNA clones. The assembled contig was $2705 \mathrm{bp}$ in length. This included a $504 \mathrm{bp} 5^{\prime}$ untranslated region featuring two possible translation start sites, an open-reading frame of $2157 \mathrm{bp}$ and a $3^{\prime}$ untranslated fragment of $44 \mathrm{bp}$ containing two putative polyadenylation signals. The most likely translation start site was assigned based on comparison of the virtual translation of the full transcript with the protein sequences of GpH-R homologs. Total length of the predicted protein is 719 amino acid residues. The first 29 C-terminal amino acid residues correspond to the putative signal peptide predicted by the SignalP program and were confirmed by comparison with other homologous receptors. The extracellular domain including the signal peptide is 350 amino acid residues. A 264 residues transmembrane domain is followed by a putative cytoplasmic tail of 105 residues.

Structural domains of the lGpH-R I were identified based on the detection of specific patterns and motifs and their limits were established relative to the alignment of the protein sequence with other vertebrate GpH-Rs (Fig. 1). 1GpH-R I shows the typical structural domain composition of the gnathostome GTH- and TSH-Rs: extracellular domain, rhodopsin-like transmembrane domain, and cytoplasmic segment domain. In the extracellular domain of the lGpH-R I were also identified a Cys-rich N-terminal domain followed by a LRRcontaining region and a C-terminal Cys-rich region. Putative N-glycosylation sites in positions 86,207 , and 285 in the extracellular domain and one putative $\mathrm{N}$-glycosylation site have been predicted at position 651 in the cytoplasmic segment of the receptor. Seven hydrophobic helical segments (Fig. 1, TM1-7), ca 20 residues in length are linked by three intracellular and three extracellular (EL) loops. A disulfide bridge between Cys residues located in EL1 and EL2 is also important for stabilization of the receptor conformation. The C-terminal end of the third transmembrane helix harbors a protein motif shared by all members of the GPCR superfamily. The Cys residue in position 630 matches the well-conserved Cys residue shown to be palmitoylated and anchored to the cell membrane in the rest of the members of the GpH-R family.

Globally, the IGpH-R I has a high-sequence identity with gnathostome receptors as calculated based on the ClustalW alignment of $46 \mathrm{GpH}-\mathrm{R}$ amino acid sequence with the virtual translation of lGpHR I coding sequence. The lowest identity was found for salmon TSH-R (as low as $7 \%$ identity) compared with the highest calculated for canine TSH-R ( $50 \%$ identity). With the exception of salmon TSH-R, the identity varies between $44 \%$ (salmon LH-R) and 50\% (dog TSH-R) showing the higher values for TSH- and FSH-Rs. Comparison of lGpH-R I with fish receptors resulted in the lowest identity values for all GpH-Rs.

Forty-nine vertebrate $\mathrm{GpH}-\mathrm{R}$ protein sequences were used for reconstruction of the molecular phylogenetic relationships within this class of proteins, using the $\mathrm{GpH}-$ $\mathrm{R}$ isolated from sea anemone (Anthopleura elegantissima)

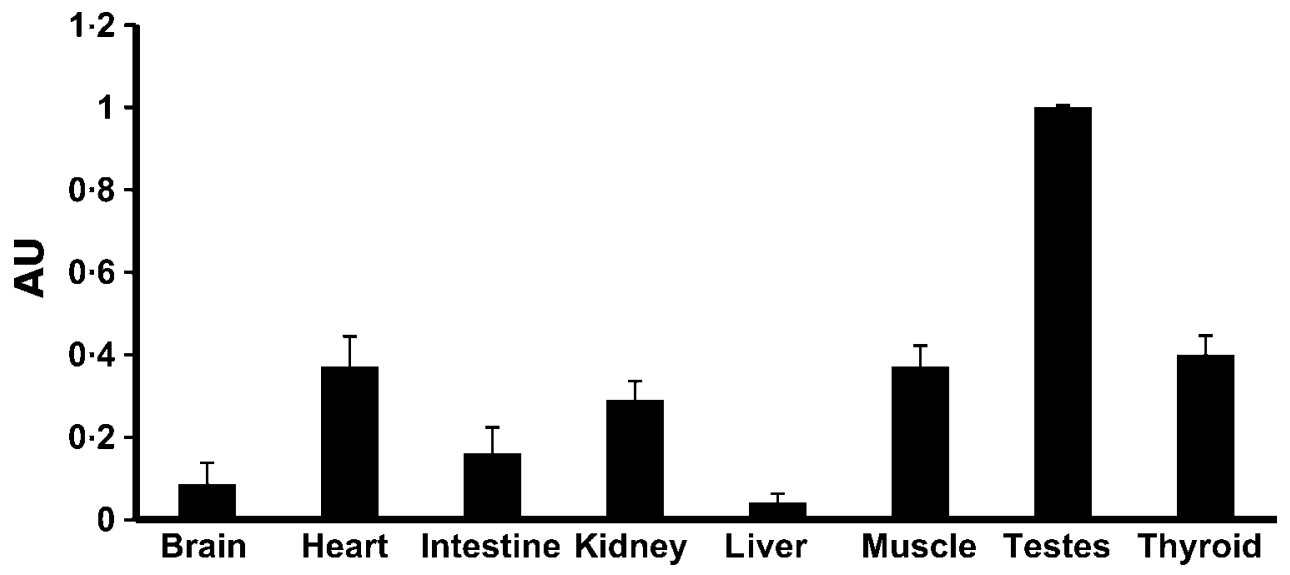

Figure 2 Semiquantitative RT-PCR for estimation of the tissue expression pattern of IGpH-R I. Total RNA samples were DNase treated, then their concentration normalized relative to either 28S rRNA or total RNA amount. RNA samples were amplified in one-tube RT-PCR experiments in parallel with no-RT controls. The graph shows results from at least three experiments with the total RNA extracted from different animals. The $Y$-axis is scaled in arbitrary units (AU) representing the ratio of each tissue RT-PCR signal to the RT-PCR signal of testis sample obtained in the same experimental run. 
(Nothacker \& Grimmelikhujzen 1993) as an outgroup. The resulting tree (Fig. 4) has the usual topology of the phylogenetic trees most often reported for this family of proteins, with two major clades mirroring the functional distinction between the TSH-Rs and GTH-Rs. lGpH-R I and the GTH-Rs form a monophyletic group, the lamprey receptor being the earliest diverged member of this clade.

The highest level of the receptor transcript was identified in the lamprey testis tissue using RT-PCR.
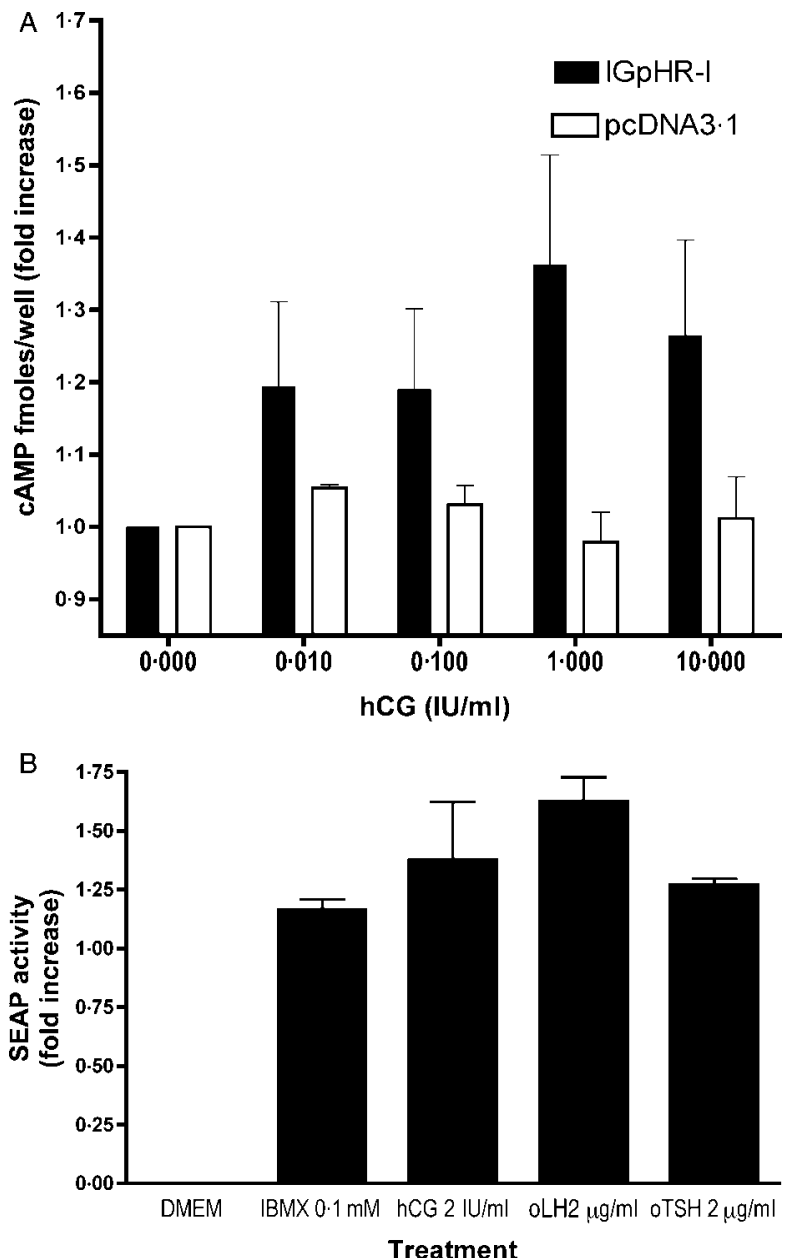

Figure 3 (A) CAMP accumulation in response to human chorionic gonadotropin (hCG) stimulation of COS-7 cells transiently transfected with a pcDNA3.1/V5/His expression construct of IGpH-R I. On the $Y$-axis, the fold increases in intracellular concentration of cAMP relative to the basal level are shown. On the $X$-axis, the concentration of hormone in the stimulation medium (IU/ml) is shown. (B) Comparison of activation of secreted alkaline phosphatase reporter gene activation following treatment of COS-7 transiently transfected cells with IBMX, hCG, oLH (ovine luteinizing hormone), and oTSH (ovine thyroid stimulating hormone). The values on the $Y$-axis represent the ratio (fold increase) between the results obtained for IGpH-R I and pcDNA3. 1 transfected cells, after normalization with respect to the response to treatment with $5 \mu \mathrm{M}$ forskolin.
Detectable levels of the receptor transcript were also shown in brain, heart, intestine, kidney, liver, muscle, and thyroid as depicted in Fig. 2. This figure shows the relative levels of the $1 \mathrm{GpH}-\mathrm{R}$ I signal in different tissues calculated as a percentage of the RT-PCR signal found in the testis samples.

Incubation of COS-7 cells with increasing amounts of hCG induced an increase in the levels of intracellular cAMP amounts determined by RIA. However, the differences over the basal level were slight (Fig. 3A). Indirect estimation of cAMP synthesis induced by increasing amounts of $1 \mathrm{GpH}-\mathrm{R}$ I transfected into COS-7 cells showed an increase in the basal level of cAMP with the amount of $1 \mathrm{GpH}-\mathrm{R}$ I plasmid (Table 2) suggesting that the lamprey receptor may constitutively induce activation of the cAMP signaling at least in a mammalian cell line. Comparison between the abilities of different glycoprotein hormones to induce the cAMP-dependent secretion of the reporter protein in the medium showed a higher response for mammalian (ovine) $\mathrm{LH}$ and TSH compared with chorionic gonadotropin.

\section{Discussion}

The deduced protein sequence of a 719 amino acid GpH-R (lGpH-R I) was determined from a $2705 \mathrm{bp}$ cDNA clone isolated from the testes tissue of one of the most ancient vertebrate species, the sea lamprey. The key motifs, sequence comparisons, and characteristics of the identified GpH-Rs reveal a mosaic of features common to all other classes of $\mathrm{GpH}-\mathrm{Rs}$ in vertebrates. The $1 \mathrm{GpH}-\mathrm{R}$ I was shown to activate the cAMP in response to the treatment with mammalian glycoprotein hormones of transiently transfected COS-7 cells. The highest expression of the receptor transcript was demonstrated in the lamprey testes using RT-PCR. Expression of the receptor transcript was also shown in lower amounts in brain, heart, intestine, kidney, liver, muscle, and thyroid. The high expression of lGpH-R I in the testis and the high similarity with gnathostome GTH-Rs suggest that lGpH-R I functions as a receptor for lamprey GTH.

The total length of lGpH-R I (719aa) is intermediary between the lengths of the GTH- and TSH-Rs from gnathostomes (695 and 750 on average) (Kumar \& Trant 2001, Oba et al. 2001). The differences are due in most part to the differences in the number of residues in the ectodomain and cytoplasmic domain compared with the other GpH-Rs. lGpH-R I has the shortest extracellular domain (estimated at 320 residues without the signal peptide) compared with around 350 residues in GTH-Rs and around 400 in TSH-Rs. Its cytoplasmic domain is correspondingly the longest in the family (estimated at 106 residues, compared with around 80 in TSH-Rs, 70 in LH-Rs, and only 60 in FSH-Rs). 
Table 2 Basal cAMP levels in COS-7 cells transiently transfected with increasing amounts of IGpH-R I or pcDNA3.1 and pCRE-SEAP reporter plasmid. The cAMP level is estimated indirectly from the activity of secreted alkaline phosphatase (SEAP) into the culture medium due to the activation of its transcription by intracellular cAMP. The enzyme activity was determined spectrophotometrically using pNPP as chromogenic substrate. The optical density readings were normalized in respect to the response to $5 \mu \mathrm{M}$ forskolin treatment determined under the same experimental conditions

IGpH-R I basal cAMP- $\beta$

No IBMX

With IBMX

pcDNA3.1 basal cAMP

No IBMX

With IBMX
Plasmid amount $(\mu \mathrm{g})$

\begin{tabular}{lllllll}
\hline 0.05 & 1.0 & 2.0 & & 4.0 & 6.0 & \\
0.13 & 0.11 & 0.16 & 0.2 & 0.24 & 0.27 \\
0.22 & 0.19 & 0.23 & 0.26 & 0.29 & 0.32 \\
0.13 & 0.12 & 0.13 & 0.13 & 0.14 & 0.14 \\
0.26 & 0.23 & 0.22 & 0.20 & 0.22 & 0.23 \\
\hline
\end{tabular}

The N-terminal half of $1 \mathrm{GpH}-\mathrm{R}$ I has the lowest identity with the vertebrate GpH-Rs. The potential functionally important residues at different sites in the extracellular domain of $1 \mathrm{GpH}-\mathrm{R}$ I are unique to this receptor in the context of the conservation of the global domain organization. This might be of particular significance for understanding the functional divergence of this class of receptors. The region is important for ligand binding and contains the determinants of the specificity of binding of agonists to the GpH-Rs (Combarnous 1992, Bhowmick et al. 1996, Grossman et al. 1997, Ascoli et al. 2002).

The Arg in position 192 in lGpH-R I (Fig. 1(i)) corresponds to a well-conserved Lys residue in TSH-R and LH-R. It has been shown that mutation of the human TSH-R Lys residue in this position to Arg abolishes the ligand specificity of the receptor leading to increased sensitivity of the human TSH-R to chorionic gonadotropin (hCG) (Dufau 1998, Farid et al. 2000). Two other interesting residues are the Lys and Asp residues in positions 89 and 91 respectively of the lGpH-R I, located downstream a glycosylation site, which IGpH-R I shares with TSH-Rs (Fig. 1(ii)). They correspond to Arg and Tyr residues in the TSH-R consensus (positions 80 and 82 respectively in rat TSH-R). It has been shown (Smits et al. 2003) that concomitant mutations Arg80Lys + Tyr82Glu results in a gain of sensitivity of TSH-R to hCG.

The rat LH-R LeuXxxCysXxxGly motif close to exons 1-2 junction shown to be crucial for $\mathrm{LH} / \mathrm{hCG}$ hormone binding (Hong et al. 1998) matches the lGpHR I ValXxxCysXxxGly residues and is distinct from the TSH-R consensus in the same position. Ala substitution of any of these residues resulted in no hormone binding, although the receptor was successfully expressed on the cell membrane.

Costagliola et al. (2002) described a specific motif in TSH-R and downstream of the C-terminal Cys-rich domain. The motif with consensus sequence YDY is the site for sulfation at one of the Tyr residues and located upstream at the start of the transmembrane domain. Its presence has been shown to be a requirement for binding and activation of TSH-R and suggested to play a similar role in GTH-Rs. The motif is very well conserved in TSH-Rs, common in mammalian LH-Rs and present only sporadically in FSH-Rs (where the consensus FDY can be found instead). This motif is missing in lGpH-R I, which is another element differentiating the lGpH-R I from vertebrate TSH-Rs in an apparent contradiction with the global similarity results.

The glycosylation of the extracellular domain of GpH-Rs has been shown to be important for the function of these receptors (Dufau 1998). The presence of only three glycosylation sites in the extracellular domain differentiates the lamprey receptor from all other known GpHs, which have six (TSH-R and LH-R) or five (FSH-R) such motifs in this domain. However, the glycosylation motif in position 86 aligns with a similar motif in TSH-Rs, the one in position 207 is common to all GpH-Rs, while the NLT glycosylation motif at the N-terminal end of the C-terminal Cys-rich domain is common in most FSH-Rs.

\section{Tissue expression pattern and functional assay}

Initially, the receptors for GpHs seemed to be characterized by their high tissue expression specificity (Dufau 1998, Ascoli et al. 2002) in accordance with their tissuespecific physiological roles (Hsu et al. 1998). Later, a couple of examples of 'ectopic' expression of these receptors in mammals have been described by various authors (Endo et al. 1995, Hermey et al. 1999, Eblen et al. 2001). It has become accepted that LH-Rs are more prone to show extragonadal expression and are less specific, while the FSH-R and TSH-R genes are under a more stringent control over their tissue expression and binding specificity. Identification and cloning of the GTH- and TSH-R homologs in fish species seemed to 


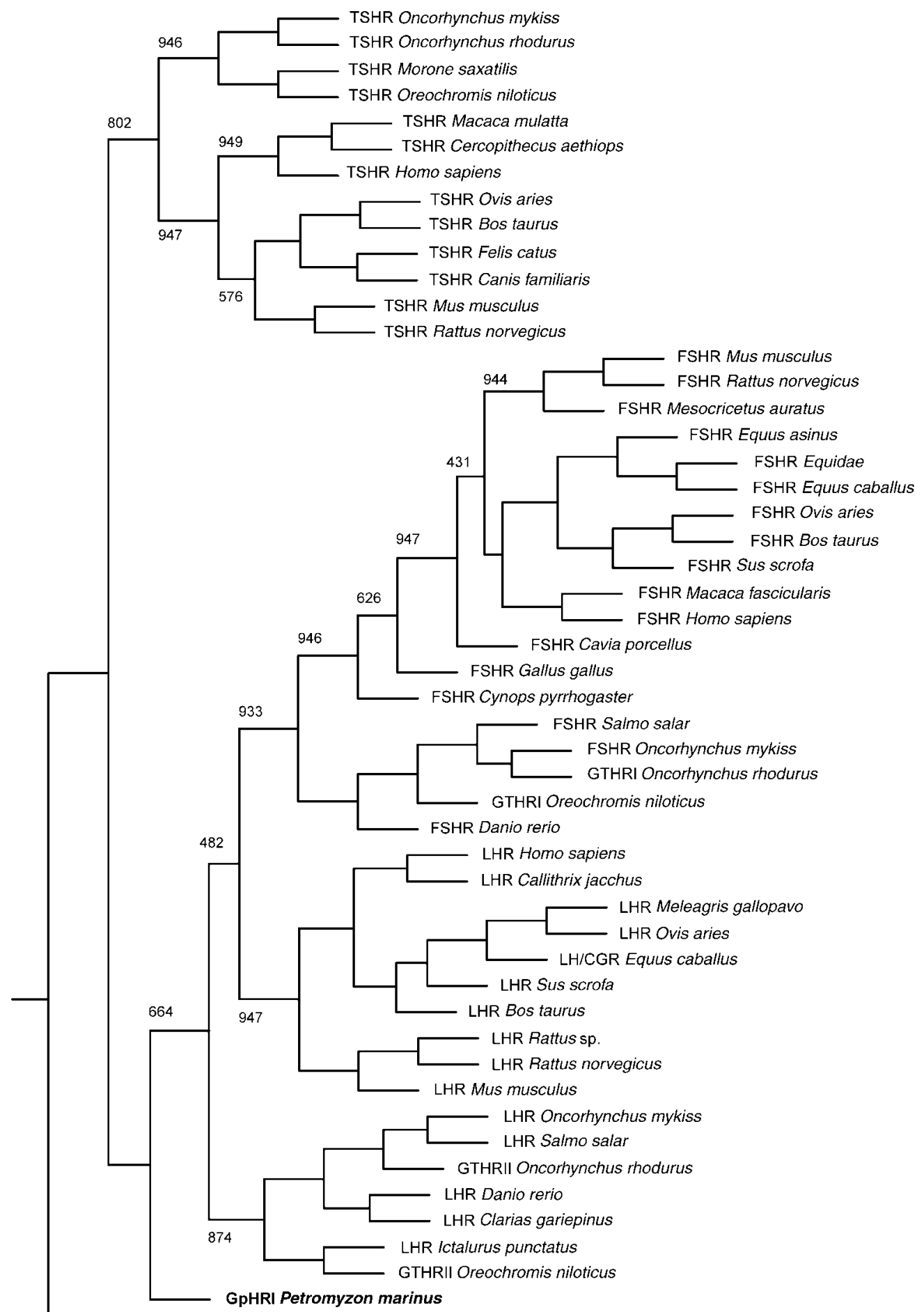

GpHR Anthopleura elegantissima

Figure 4 Representation of the molecular phylogenetic relationships between members of the glycoprotein hormone receptor protein family. This is a consensus tree derived from maximum parsimony trees calculated for 1000 bootstrap replica of an original set of 49 protein sequences of vertebrate and invertebrate (sea anemone, Anthopleura elegantissima) $\mathrm{GpH}-\mathrm{Rs}$. Branches with bootstrap scores lower than 950 are labeled with the corresponding values. 
confirm this paradigm, although the diversity of tissues where the transcripts of GpH-Rs, in particular, of fish LH-Rs could be detected has increased (Bogerd et al. 2001, Kumar et al. 2001, Vischer \& Bogerd 2003, Vischer et al. 2003). The low specificity in tissue expression of $1 \mathrm{GpH}-\mathrm{R}$ I seems to confirm an evolutionary trend of decreased stringency of gene expression control in ancient vertebrate lineages. Nevertheless, its highest level of expression in the testicular tissue of the male lamprey supports the hypothesis of the involvement of lGpH-RI in the endocrine control of reproduction in lamprey in completion of a hypothalamopituitary-gonadal axis as known for all jawed vertebrates (Dufau 1998, Ascoli et al. 2002).

\section{Conclusion}

\section{Evolution of glycoprotein hormone receptors}

Overall, analysis of the primary structural features of the lGpH-R I reveals characteristics, which support the hypothesis of its homology with gnathostome GTH-and TSH-Rs. On the other hand, it does not offer strong support for its classification in either of these two groups. The vertebrate $\mathrm{GpH}-\mathrm{Rs}$ have been divided into two subclasses based primarily on the functional criterion of implication in two distinct endocrine control axes in gnathostomes. It has been speculated that the GpH-R evolved from possibly ligandless $\mathrm{GpH}-$ Rs, whose function was accomplished by (non-hormonal) regulation of their constitutive activity. The increased specificity of the receptors in later evolved vertebrates seems to be associated with the decrease in their constitutive activity in the context of correlated mutations in receptor and ligand leading to increased thermodynamic stability of the complex (Farid \& Szkudlinski 2004). Identification of new leucine-rich repeat-containing $\mathrm{G}$ protein-coupled receptors (LGR) in rat and human showing a very low tissue expression specificity and high constitutive activity seems to confirm this scenario (Hsu et al. 1998, 2000).

The lGpH-R I described in this paper is the first receptor for glycoprotein hormones described in agnathans. It is highly similar and the key motifs present in its sequence suggest that it is likely a homolog of the vertebrate gonadotropin and thyrotropin receptors. However, it does not lend itself to a formal classification in one of these two gnathostome GpH-R groups. Its detectable response to a mammalian gonadotropin indicates that it is a functional receptor that has a role in the sea lamprey reproductive physiology. To date, there has been no evidence to support the presence of TSH in this species and only one GTH-like hormone has been identified (Sower et al. 2006). It has previously been shown that treatment with salmon gonadotropin extract induces an increase not only in plasma estradiol concentrations, but also in plasma thyroxine concentrations in male and female adult sea lampreys (Sower et al. 1985). Based on these results, it has been hypothesized (Sower et al. 2006) that the thyroid and the gonads of the lamprey are under a pituitary control mediated by the same glycoprotein hormone. From this perspective, the endocrine physiology of lamprey antecedes the evolution of the pituitary-gonadal and pituitary-thyroid axes in gnathostomes (jawed vertebrates). However, further investigations are required for characterization of the ligand binding and signal transduction activities.

\section{Acknowledgements}

We thank Matthew Silver, Scott Kavanaugh, Mike Baron, Geoff Bushold, Beverly Valeriani, Mark Santos, Nathaniel Nucci, Adam Root, Drs Kara Lee and Mickie Powell for their assistance with the collection of lamprey tissues. We thank Dr William Moyle for his generous gift of important reagents, as well as for his valuable comments.

\section{Funding}

This research has been supported by the National Science Foundation (IBN0421923) to S A S and Japan Society for the Promotion of Science and Grant-in-Aid for International Scientific research (No. 11691132) and for Basic Research (Nos 12556033 and 15370029) to $\mathrm{H} \mathrm{K}$ from the Ministry of Education, Japan. This is Scientific contribution No. 2280 from the New Hampshire Agricultural Experiment Station. The authors declare that there is no conflict of interest that would prejudice the impartiality of this scientific work.

\section{References}

Abramoff MD, Magelhaes PJ \& Ram SJ 2004 Image processing with Image. Journal of Biophotonics International 11 36-42.

Ascoli M, Fanelli F \& Segaloff DL 2002 The Lutropin/Choriogonadotropin Receptor. A 2002 Perspective. Endocrine Reviews 23 141-174.

Attwood TK, Beck ME, Flower DR, Scordis P \& Selley JN 1998 The PRINTS protein fingerprint database in its fifth year. Nucleic Acids Research 26 304-308.

Attwood TK, Bradley P, Flower DR, Gaulton A, Maudling N, Mitchell AL, Moulton G, Nordle A, Paine K, Taylor P et al. 2003 PRINTS and its automatic supplement, prePRINTS. Nucleic Acids Research 31 400-402.

Bhowmick N, Huang J, Puett D, Isaacs NW \& Lapthorn AJ 1996 Determination of residues important in hormone binding to the extracellular domain of the luteinizing hormone/chorionic gonadotropin receptor by site-directed mutagenesis and modeling. Molecular Endocrinology 10 1147-1159. 
Bogerd J, Blomenrohr M, Andersson E, van der Putten HH, Tensen CP, Vischer HF, Granneman JCM, Janssen-Dommerholt C, Goos HJTh \& Schulz RW 2001 Discrepancy between molecular structure and ligand selectivity of a testicular follicle-stimulating hormone receptor of the African catfish (Clarias gariepinus). Biology of Reproduction 64 1633-1643.

Bucher P \& Bairoch A 1994 A generalized profile syntax for biomolecular sequences motifs and its function in automatic sequence interpretation. In ISMB-94; Proceedings of the 2nd International Conference on Intelligent Systems for Molecular Biology, pp 53-61. Eds R Altman, D Brutlag, P Karp, R Lathrop \& D Searls. Menlo Park, CA: AAAI Press.

Combarnous Y 1992 Molecular basis of the specificity of binding of glycoprotein hormones to their receptors. Endocrine Reviews 13 670-691.

Costagliola S, Panneels V, Bonomi M, Koch J, Many MC, Smits G \& Vassart G 2002 Tyrosine sulfation is required for agonist recognition by glycoprotein hormone receptors. EMBO Journal 21 504-513.

Dufau ML 1998 The luteinizing hormone receptor. Annual Review of Physiology 60 61-96.

Eblen A, Bao S, Lei ZM, Nakajima ST \& Rao CV 2001 The presence of functional luteinizing hormone/chorionic gonadotropin receptors in human sperm. Journal of Clinical Endocrinology and Metabolism 86 2643-2648.

Endo T, Ohta K, Haraguchi K \& Onaya T 1995 Cloning and functional expression of a thyrotropin hormone receptor cDNA from rat fat cells. Journal of Biological Chemistry 270 10833-10837.

Farid NR \& Szkudlinski MW 2004 Minireview: structural and functional evolution of the thyrotropin receptor. Endocrinology 145 4048-4057.

Farid NR, Kascur V \& Balazs C 2000 The human thyrotropin hormone receptor is highly mutable: a review of gain-of-function mutations. European Journal of Endocrinology 143 25-30.

Felsenstein J 1989 PHYLIP-Phylogeny Inference Package (Version 3.2). Cladistics 5 164-166.

Gorbman A \& Sower SA 2003 Evolution of the role of GnRH in animal (Metazoan) biology. General and Comparative Endocrinology 134 207-213.

Grossman M, Weintraub BD \& Szkudlinski MW 1997 Novel insights into the molecular mechanisms of human thyrotropin action: structural, physiological, and therapeutic implications for the glycoprotein hormone family. Endocrine Reviews 18 476-501.

Hermey G, Methner A, Chica SH \& Hermans-Borgmeyer I 1999 Identification of a novel seven-transmembrane receptor with homology to glycoprotein receptors and its expression in the adult and developing mouse. Biochemical and Biophysical Research Communications 254 273-279.

Hong S, Phang T, Ji I \& Ji TH 1998 The amino-terminal region of the luteinizing hormone/choriogonadotropin receptor contacts both subunits of human choriogonadotropin. I. Mutational analysis. Journal of Biological Chemistry 273 13835-13840.

Hsu SY, Liang S-G \& Hsueh AJW 1998 Characterization of two LGR genes homologous to gonadotropin and thyrotropin receptors with extracellular leucine-rich repeats and a $G$ protein-coupled, seven-transmembrane region. Molecular Endocrinology 12 1830-1845.

Hsu SY, Kudo M, Chen T, Nakabayashi K, Bhalla A, van der Spek PJ, van Duin M \& Hsueh AJW 2000 The three subfamilies of leucinerich repeat-containing $\mathrm{G}$ protein-coupled receptors (LGR): identification of LGR6 and LGR7and the signaling mechanism for LGR7. Molecular Endocrinology 14 1257-1271.

Kawauchi H, Suzuki K, Itoh H, Swanson P, Naito N, Nagahama Y, Nozaki M, Nakai Y \& Itho S 1989 The duality of teleost gonadotropins. Fish Physiology and Biochemistry 7 29-38.

Kumar RS \& Trant JM 2001 Piscine glycoprotein hormone (gonadotropin and thyrotropin) receptors: a review of recent developments. Comparative Biochemistry and Physiology 129 347-355.

Kumar RS, Ijiri S \& Trant JM 2001 Molecular biology of the channel catfish gonadotropin receptors: 2. complementary DNA cloning, functional expression, and seasonal gene expression of the folliclestimulating hormone receptor. Biology of Reproduction 65 710-717.

Kuratani S, Kuraku S \& Murakami Y 2002 Lamprey as an evo-devo model: lessons from comparative embryology and molecular phylogenetics. Genesis 34 175-183.

Li MD \& Ford JJ 1998 A comprehensive evolutionary analysis based on nucleotide and amino acid sequences of the alpha and beta-subunits of glycoprotein hormone gene family. Journal of Endocrinology 156 529-542.

Matz MV, Alieva NO, Chenchik A \& Lukyanov S 2003 Amplification of cDNA ends using PCR suppression effect and step-out PCR. Methods in Molecular Biology 221 41-49.

Moyle RW, Campbell RK, Myers RV, Bernard MP, Han Y \& Wang X 1994 Co-evolution of ligand-receptor pairs. Nature 368 251-255.

Moyle RW, Lin W, Myers RV, Cao D, Kerrigan JE \& Bernard MP 2005 Models of glycoprotein hormone receptor interaction. Endocrine 26 189-205.

Nielsen H, Engelbrecht J, ren Brunak SA \& von Heijne G 1997 Identification of prokaryotic and eukaryotic signal peptides and prediction of their cleavage sites. Protein Engineering 10 1-6.

Nothacker HP \& Grimmelikhujzen CJ 1993 Molecular cloning of a novel, putative $\mathrm{G}$ protein-coupled receptor from sea anemones structurally related to members of the $\mathrm{FSH}, \mathrm{TSH}, \mathrm{L} \mathrm{H} / \mathrm{CG}$ receptor family from mammals. Biochemical and Biophysical Research Communications 197 1062-1069.

Oba Y, Hirai T, Yoshiura Y, Kobayashi T \& Nagahama Y 2001 Fish gonadotropin and thyrotropin receptors: the evolution of glycoprotein hormone receptors in vertebrates. Comparative Biochemistry and Physiology 129 441-448.

Querat B, Sellouk A \& Salmon C 2000 Phylogenetic analysis of the vertebrate glycoprotein hormone family including new sequences of sturgeon (Acipenser baeri) beta subunits of the two gonadotropins and the thyroid-stimulating hormone. Biology of Reproduction 63 222-228.

Querat B, Arai Y, Henry A, Akama Y, Longhurst TJ \& Joss JMP 2004 Pituitary glycoprotein hormone beta subunits in the australian lungfish and estimation of the relative evolution rate of these subunits within vertebrates. Biology of Reproduction 70 356-363.

Smits G, Campillo M, Govaerts C, Janssens V, Richter C, Vassart G, Pardo L \& Costagliola S 2003 Glycoprotein hormone receptors: determinants in leucine-rich repeats responsible for ligand specificity. EMBO Journal 22 2692-2703.

Sower SA 2003 The endocrinology of reproduction in lampreys and applications for male lamprey sterilization. Journal of Great Lakes Research 29 50-65.

Sower SA, Plisetskaya E \& Gorbman A 1985 Steroid and thyroid hormone profiles following a single injection of partly purified salmon gonadotropin or GnRH analogues in male and female sea lamprey. Journal of Experimental Zoology 235 403-408.

Sower SA, Moriyama S, Kasahara M, Takahashi A, Nozaki M, Uchida K, Dahlstrom JM \& Kawauchi H 2006 Identification of sea lamprey GTH beta cDNA and its evolutionary implications. General and Comparative Endocrinology. In press.

Staden R 1996 The Staden Sequence Analysis Package. Molecular Biotechnology 5 233-241.

Suzuki K, Kawauchi H \& Nagahama Y 1988 Isolation and characterization of two distinct gonadotropins from chum salmon pituitary glands. General and Comparative Endocrinology 71 292-301.

Swanson P, Dickey JT \& Campbell B 2003 Biochemistry and physiology of fish gonadotropins. Fish Physiology and Biochemistry 28 53-59.

Szkudlinski MW, Fremont V, Ronin C \& Weintraub BD 2002 Thyroidstimulating hormone and thyroid-stimulating hormone receptor structure-function relationships. Physiology Reviews 82 473-502.

Themmen APN \& Huhtaniemi IT 2000 Mutations of gonadotropins and gonadotropin receptors: elucidating the physiology and pathophysiology of pituitary-gonadal function. Endocrine Reviews 5 551-583. 
Thompson JD, Higgins DG \& Gibson TJ 1994 CLUSTAL W: improving the sensitivity of progressive multiple sequence alignment through sequence weighting, positions-specific gap penalties and weight matrix choice. Nucleic Acids Research 22 4673-4680.

Vischer HF \& Bogerd J 2003 Cloning and functional characterization of a gonadal luteinizing hormone receptor complementary DNA from the African catfish (Clarias gariepinus). Biology of Reproduction 68 262-271.
Vischer HF, Granneman JCM \& Bogerd J 2003 Opposite contribution of two ligand-selective determinants in the N-terminal hormonebinding exodomain of human gonadotropin receptors. Molecular Endocrinology 17 1972-1981.

Received in final form 12 April 2006

Accepted 26 April 2006 